\title{
A Parameter Matching Method of the Parallel Hydraulic Hybrid Excavator Optimized with Genetic Algorithm
}

\author{
Xiaoliang Lai and Cheng Guan \\ Mechanical Design, Zhejiang University, Hangzhou 310027, China \\ Correspondence should be addressed to Xiaoliang Lai; eric.laixl@gmail.com
}

Received 22 May 2013; Accepted 31 August 2013

Academic Editor: Mahmoud Abdel-Aty

Copyright ( 2013 X. Lai and C. Guan. This is an open access article distributed under the Creative Commons Attribution License, which permits unrestricted use, distribution, and reproduction in any medium, provided the original work is properly cited.

\begin{abstract}
This paper proposed a parameter matching method based on the energy storage unit, the accumulator in the parallel hydraulic hybrid excavator (PHHE). The working condition, system structure, and control strategy of the excavator were all considered. It took the 20-ton series PHHE as the example and displayed the parameter matching course of the main components: engine, accumulator, and hydraulic secondary regulatory pump. Their installed powers were reduced after the matching course. Furthermore, the parameters of the PHHE system were optimized with the genetic algorithm to get the most suitable values for system initialization. By analyzing the simulation results, it could be concluded that the parameter matching method had an impressive improvement of the energy saving under the same working condition and brought obscure influence to the mechanism dynamics.
\end{abstract}

\section{Introduction}

Due to the global energy crisis, the energy saving became the popular research aspect. Huge fuel consumption of hydraulic excavator, the most useful machine in the construction projects, attracted researcher's interest. Even though the hydraulic excavator had used the higher-efficiency diesel engine, it had a lot of problems on the fuel consumption efficiency for a long time until the hybrid technology occurred, because the excavator had complex working condition and sharply changed load. The hybrid technology was applied in the vehicle field firstly and then was introduced into the excavator field. The topic research aspect was focused on the parallel hybrid electric excavator in the recent years whose storage unit was Ni-H battery or superelectric capacity. The $\mathrm{Ni}-\mathrm{H}$ battery was cheap in price but large in volume and its life greatly depended on the battery management system. On the other hand, the superelectric capacity had good characteristics but was expensive in price $[1,2]$. Besides, the excavator had such more fluctuating load than the vehicle system that electric scheme would not be able to compensate the difference timely. As an exploration, the hydraulic scheme was proposed to overcome the shortcomings of the electric scheme mentioned above [3-5]. The hydraulic scheme used the accumulator to replace the energy storage unit in the electric scheme. It had the advantage of high power density and easy combination with the excavator system. In addition, with the potential energy from recovery subsystem, the fuel consumption would be better due to the reduction of the energy conversation process [6-8].

Meanwhile, the change of the components in the hydraulic hybrid excavator needed a new round of choosing on their patterns and parameters. A suitable parameter matching could maximize the efficiency, reduce the volume of every component, and cut down the system's mass and price. Papers [9-11] presented their parameter matching method the electric hybrid excavator and got an obvious improvement in the energy saving compared with the unmatched pattern. But their match courses only take the restrictions as a concern to get the approximate parameters and they were designed especially for the electric scheme. The parameters were often an experience value and had a big adjustable range.

Based on the reason mentioned before, this paper proposed a parameter matching method for the parallel hydraulic hybrid excavator (PHHE). It was based on the structure, load, and the control strategy of the excavator. And a genetic 
algorithm was used for optimization to acquire more precise and suitable parameters of the components in the PHHE system.

\section{Description of the Hydraulic Hybrid System Excavator}

2.1. The Principle of the Hydraulic Hybrid System. The hydraulic hybrid system contained two power sources. One was the chemical energy generated by burning fuel in the diesel engine. The other one was the hydraulic energy generated by recycling the potential energy from gravitation. The first part was converted from mechanical energy to hydraulic energy, which was the surplus value of the engine output power. The second part was converted from gravitational potential energy to hydraulic energy, which was wasted during excavator working originally. The second part was a special form of the first part in some sense. However, the second part conversation process brought no extra load to the engine. Moreover, the conversation process would adjust the load curve, stabilize the engine speed, and improve the fuel consumption efficiency, because the process would supply energy in high load and absorb energy in low load. In this paper, the hydraulic energy only contained the boom gravitation because of its most typical and largest recoverable amount.

2.2. The Structure of the PHHE System. The structure of the hydraulic hybrid excavator system mentioned in this paper was shown in Figure 1. The multiple manifolds were the flow distribution device of the original hydraulic system. The main pump of the excavator's hydraulic system, the energy conversation unit, and the engine was connected coaxially which made up the parallel hybrid power style. The energy conversation unit, the energy storage unit and the energy controller constituted the assistant power subsystem. Here, the energy conversation unit meant the hydraulic secondary regulation component and the energy storage unit meant the hydraulic accumulator. When the energy conversation unit worked as a pump, it absorbed the surplus power of the engine and charged the energy storage unit. When the energy conversation unit worked as a motor, it supplied the lacking power of the engine and released the energy storage unit. In this system, the boom gravitational potential energy was directly charged into energy storage unit unlike the chemical energy. The chemical energy coming from the engine must be transformed by the energy conversation unit. But when the energy in the storage unit was reused, it would through the energy conversation unit only. The energy transmitted after the engine output was in the form of hydraulic fluid. The arrows in Figure 1 indicated the allowed flow direction in the hydraulic system.

\section{The Modeling and Parameter Matching Method of PHHE}

3.1. The Modeling of the Components. The diesel engine was the main power source of the whole PHHE system. Modeling

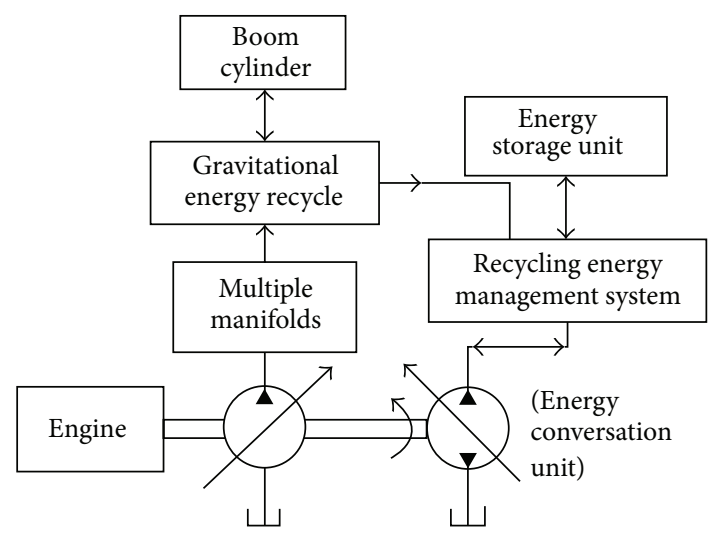

FIGURE 1: The structure of the hydraulic hybrid system.

the engine internal burning course was too complex and difficult. We simplify modeling the engine based on Newton's first law as (1)

$$
T_{l}=T_{e}-J_{e} \dot{\omega}-C_{e} \omega
$$

where $T_{l}$ was the output torque of the engine, $T_{e}$ was the torque that forces on the axial, $J_{e}$ was equivalent engine inertia, $C_{e}$ was equivalent viscous damping, and $\omega$ was the engine angular velocity.

In this system, the energy storage unit meant the accumulator. We considered that the energy absorbing/releasing courses were both under the heat insulation. As a result, the accumulator was modeled as (2)

$$
\Delta V=V_{a} \cdot\left(1-\left(\frac{P_{a}}{P}\right)^{1 / n}\right) .
$$

And the change of the energy stored in the accumulator could be calculated as (3)

$$
F=\frac{P_{a} V_{a}}{n-1} \cdot\left[\left(\frac{P}{P_{a}}\right)^{(1-n) / n}-1\right],
$$

where $P_{a}$ was the accumulator precharge pressure, $P$ was the accumulator real-time pressure, $V_{a}$ was the accumulator volume, $\Delta V$ was the difference between the precharge volume and the real-time volume, and $n$ was the gas polytrophic index which was selected as 1.4 .

In this system, the energy conversation meant the secondary regulatory pump which could work as pump or motor by adjusting the swash plate in different quadrant. The flow could be expressed as (4)

$$
Q_{m}=\frac{\pi}{4} d^{2} z n D \tan \beta
$$

where $Q_{m}$ was the flow of the secondary regulatory pump, $d$ was the diameter of the plunger, $z$ was the quantity of the plunger, $n$ was the speed of the axial, $D$ was the circle diameter of the plunger distribution, and $\beta$ was the angle of the swash plate. And the torque was expressed as (5)

$$
T_{m}=\frac{\Delta P \cdot Q_{m}}{2 \pi n}
$$


where $T_{m}$ was the theory torque of the secondary regulatory pump and $\Delta P$ was the difference between the inlet and the outlet pressures of the pump. Because the secondary regulatory pump could work as two states, the efficiency should be modeled separately. Equation (6) represented the efficiency under pump state and (7) represented the efficiency under motor state:

$$
\begin{gathered}
\eta_{p}=\frac{Q_{m}-\Delta Q}{Q_{m}} \\
\eta_{m}=\frac{Q_{m}}{Q_{m}+\Delta Q},
\end{gathered}
$$

where $\eta_{p}$ and $\eta_{m}$ were the efficiency rates and $\Delta Q$ was the difference between the inlet and outlet of the secondary regulatory pump.

In this system, the energy consumption unit meant the hydraulic cylinder. It could be described as (8)

$$
M \ddot{x}+B \dot{x}+F(t)=p_{1} A_{1}-p_{2} A_{2},
$$

where $x$ was the displacement of the piston, $M$ was the equivalent mass on the piston rod, $B$ was the cylinder viscous damping coefficient, $F(t)$ was the force on the cylinder, $p_{1}$ was the pressure of the chamber without rod, $A_{1}$ was the area of the chamber without rod, $p_{2}$ was the pressure of the chamber with rod, and $A_{2}$ was the area of the chamber with rod.

3.2. The Parameter Matching Method. Due to the low energy density and high power density of the PHHE system, the storage volume and precharge pressure of the accumulator became the most important parameters. They decided the working ability limit of the assistant subsystem. At the same time, the parameters of the accumulator, the secondary regulatory pump, the engine, and the other new components should satisfy different, sometimes even opposite, requirements. But the principles of parameters matching should be fixed as below:

(1) the working ability of the excavator should not decrease after the parameters matching,

(2) every component should work in; high-efficient area as much time as possible.

The parameter matching was an optimal course for the specific system. The load, the structure, and the control strategy of the PHHE system would bring influences to the optimal course.

3.2.1. The Working Condition of the Excavator. The load curve of a $20 t$ excavator was shown in Figure 2. Obviously, the load had a periodicity while the excavator was operated through mining, upgrading, turning, and discharging. On the contrary, it sharply changed between different motions.

The aim of the parameter matching was lower the fuel consumption and reduce the dimension in the case of guaranteeing the normal operation under the complex working condition. It could be described as (9)

$$
\min \text { : fuel }\left(T_{e}, n, g e\right), V\left(V_{\mathrm{acc}}, V_{e}, V_{m}\right),
$$

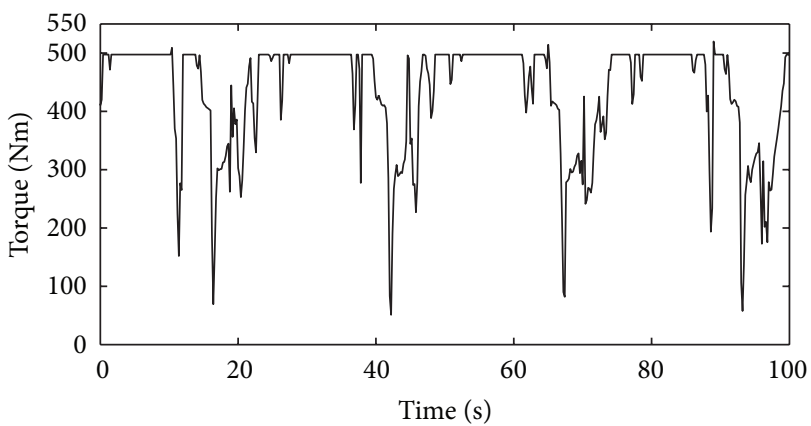

FIgURE 2: The load curve of the $20 t$ excavator.

where $n$ was the engine speed, ge was the fuel consumption rate, $V_{\text {acc }}$ was the accumulator dimensions, $V_{e}$ was the engine dimensions, and $V_{m}$ was the motor dimensions.

3.2.2. The Constraints of the Parameter Match. In this paper, the parallel hybrid system must meet the dynamic characteristics in order to maintain the original excavator work characteristics. The power was the most important requirement which should be satisfied firstly as (10)

$$
P_{e}+P_{m}=P_{p} \geq P_{l}
$$

where $P_{e}$ was the engine power, $P_{m}$ was the secondary regulatory pump power, $P_{p}$ was the main pump power, and $P_{l}$ was the load power. Since the engine, the main pump, and the secondary regulatory pump were connected coaxially, the torque constraint was got as (11)

$$
T_{e}+T_{m} \geq T_{p},
$$

where $T_{m}$ was the torque of the secondary regulatory pump and $T_{p}$ was torque of the main pump. The accumulator played multiple roles in this system. When it was charged, its pressure was regarded as a resistant source; otherwise it was a power source. In particular when accumulator absorbed the boom gravitational potential energy, the parameters of the accumulator determined the speed and finish time of the motion of the boom directly. In order to maintain the motion, (12) and (8) must be considered when the boom gravitational potential energy is recovered by the accumulator:

$$
x=\int_{0}^{t_{i}^{\prime}} \dot{x} \cdot d t .
$$

The time of the excavator motions should meet

$$
\left|t_{i}^{\prime}-t_{i}\right| \leq \varepsilon_{i}
$$

where $t_{i}$ was the original time of the boom motion and $\varepsilon_{i}$ was the allowed value of the time difference defined by the operator.

3.2.3. The Key of the Parameter Match. In PHHE system, the energy storage unit accumulator became the key component. Its parameters should be determined earlier than the assistant 
power source. It was the most obvious difference of the parameter matching process between the PHHE system and the hybrid electric excavator system.

From (8), (5), it was known that when the accumulator worked as a resistance source absorbing the boom gravitational potential energy, the higher the accumulator internal pressure $P_{a}$ was, the shorter the braking time was. At the same time, $P_{a}$ also had an effect on the pressure of the chamber with the rod. The pressure should avoid reaching the value of the system overflowing which would bring extra energy loss. When the accumulator worked in the hybrid subsystem, the accumulator internal pressure $P_{a}$ became the input pressure of the secondary regulatory pump. The higher pressure might reduce the limit displacement of the secondary regulatory pump to create the same requirement torque value.

So it could be seen that whenever the accumulator worked in potential energy recovering system or hybrid subsystem, the high pressure was recommended.

From (2), (3), and (8) it was known that the energy storage capacity and precharge pressure have a parabolic relationship. Improper precharge pressure would weaken the energy storage capacity of the key component accumulator which determined the ability of the PHHE system.

\section{The Realization of Parameter Matching}

This paper practiced a parameter matching process for a 20ton series excavator by considering the matching principle and constraints listed before.

4.1. The Choice of the Primary Power Source. Although the accumulator was the key component of the PHHE system, the engine was still the main power source which should be chosen firstly to satisfy the average power requirement. From the data of Figure 2, the average power requirement of a 20ton excavator that operated under heavy working condition could be calculated as (14)

$$
\bar{P}_{l}=\frac{1}{T} \int P(t) d t=95.8 \mathrm{kw},
$$

where $P_{l}$ was the average requirement power and $T$ was the total time. Considering the safety factor, the engine rated power and rated speed were selected as $118 \mathrm{kw}$ and $2200 \mathrm{r} / \mathrm{m}$.

4.2. The Choice of the Key Energy Storage Device. The accumulator had different styles such as piston style, bladder style, spring style, and gravity style that suited variety of situations. In PHHE system, the bladder accumulator was selected because of its quick response, big specific volume, and easy precharging pressure set. Further, the inert nitrogen, the gas in the bladder, had more security features in the high temperature and vibration environment. The precharge pressure of the accumulator determined the lowest output pressure and the maximum energy storage. Meanwhile, the pressure affected the characteristics of the recycle system absorbing the potential energy. According to the area ratio of the cylinder, the maximum pressure of the accumulator should not exceed $25 \mathrm{MPa}$ to avoid the pressure of the chamber with rod exceed the system overflow value and the minimum pressure just need satisfying the constraint equations.

4.3. The Choice of the Energy Conversation Unit. When the accumulator had been chosen, the assistant secondary regulatory pump was selected almost because the lowest pressure of the accumulator determined the lowest rate displacement of the secondary regulatory pump. From (4), (5), the secondary regulatory pump had to make the displacement big enough to ensure that the torque difference was compensated when the accumulator pressure gets lower. So, the displacement of secondary regulatory pump was calculated as $123.77 \mathrm{~cm}^{3}$ under the extreme condition. By searching in the product list, we selected the most suitable product, whose displacement was $140 \mathrm{~cm}^{3}$ and maximum rotation speed was $3250 \mathrm{r} / \mathrm{m}$.

\section{The Optimization with GA}

From the last section, we had determined several important parameters which were constrained by the technical requirements. But to acquire the best balance between energy saving effect and economy, there were many parameters that should be chosen carefully such as the bladder accumulator's volume, precharging pressure, and engine's target speed.

Because the hybrid excavator's working cycles were nonlinear and impossible to describe by some specific formulas, the only things we could know were the parameters we set and the result we measured. By considering these adverse conditions, after comparing the popular optimized algorithms, we chose the genetic algorithm to optimize the accumulator's volume and the engine target speed since the method did not need a precise certain equation for a whole complex system [12-14].

The genetic algorithm objective function was showed as

$$
\begin{gathered}
F=f_{1} \alpha+f_{2}(1-\alpha), \\
f_{1}=\frac{G_{h}}{G_{0}} \\
f_{2}=\left(\frac{P_{h}}{P_{0}}\right)^{\varphi},
\end{gathered}
$$

where $\alpha$ was the weight coefficient, $G_{h}, G_{0}$ were the fuel consumption ratios of the hybrid system and the normal system, and $P_{h}, P_{0}$ were the prices of the hybrid system and the normal system. We selected 120 as the number of the generation, 20 as the number of the population size, 0.75 as the number of the crossover rate, and 0.01 as the number of the mutation rate.

\section{The Analysis of the Simulation Result}

We built the simulation model in the Matlab software by considering the mathematical equations above and used the double working point control strategy to examine the effect of the parameter matching method proposed in this paper [15].

The strategy was showed in Figure 3. After the excavator starting initialization, the engine would be controlled at the 


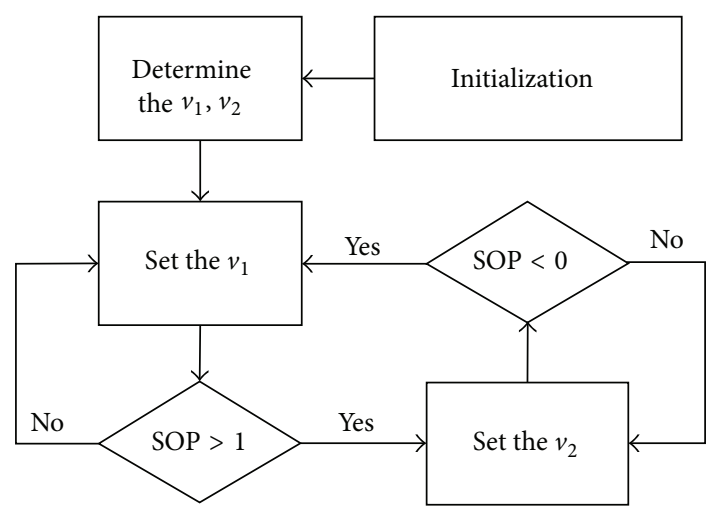

FIGURE 3: Double working points control strategy.

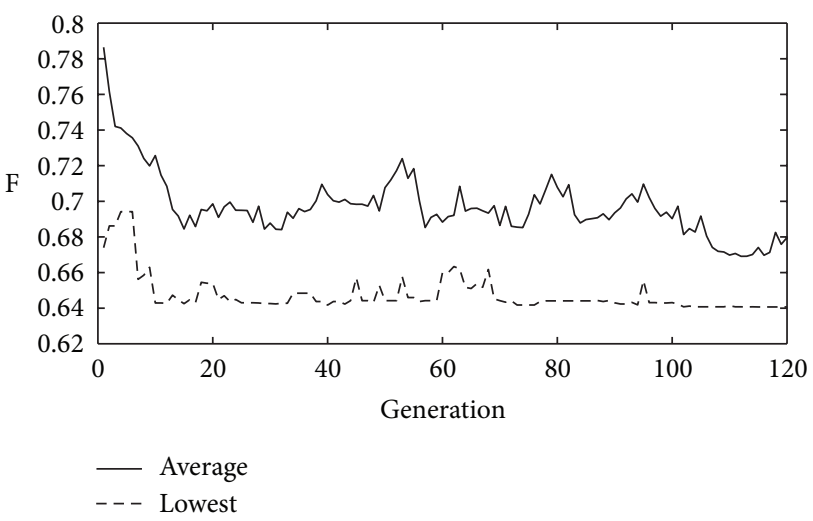

FIGURE 4: The Average and lowest values in every generation.

two selected aim speed points $v_{1}$ and $v_{2}$ depending on the value of SOP, which indicated the energy storage state of the accumulator.

By optimizing with GA method, the function value mentioned in (9), (15) was showed in Figure 4. There were two lines in the figure, the average line which was the average function value of every generation and the lowest line which was the best function value in every generation. After 100th generation, the average and lowest values both approached the best values during the optimization course. In the 120th generation, the average vale was 0.6797 and the lowest value was 0.6407 . We chose the parameters of the accumulator volume (50 L) and the engine second target speed (2035 rpm) when the 120th lowest function value occurred to analyze the parameter matching method.

Figures 5 and 6 presented the work state and the effect of the parameter matching method, respectively. From Figure 5, we could find that the accumulator plays a role of absorbing surplus energy and providing lacking energy during the work of the excavator. And it illustrated that the PHHE system was following the double working point control strategy showed in Figure 3. The Figure 6 compared the average ge value which indicated the fuel consumption directly among the normal excavator, PHHE system, and the PHHE system optimized with the GA method. The latter two had an obviously better ge than the normal excavator and the last

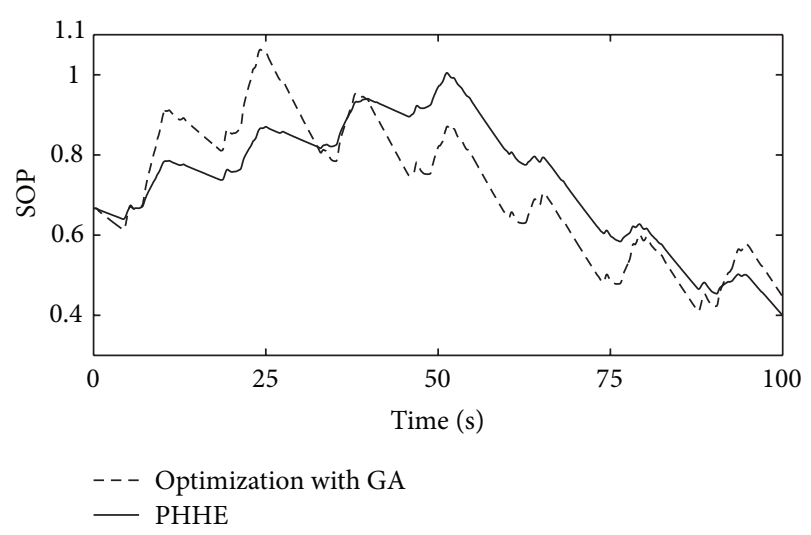

FIGURE 5: The SOP comparison between hybrid and optimized excavator

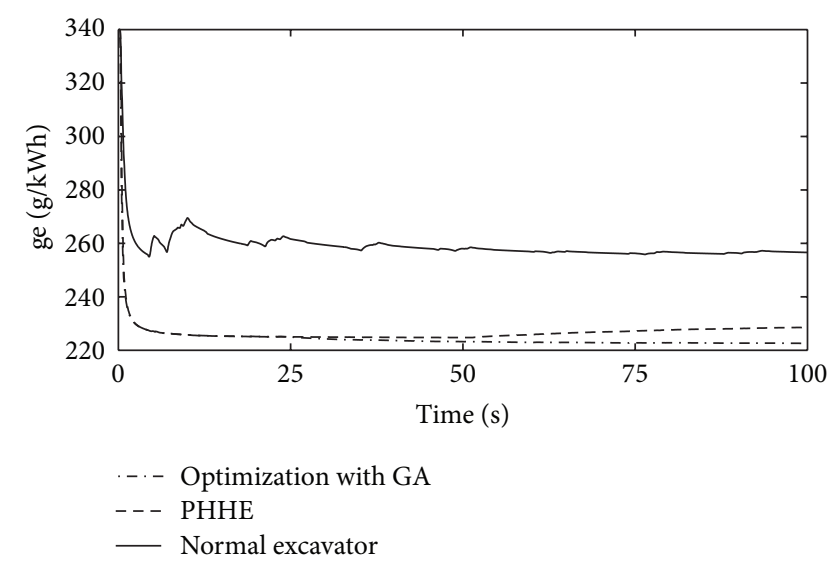

Figure 6: The ge comparison among the normal, hybrid, and optimized excavator.

one had a little better ge than the PHHE system without GA. The accuracy stabilized average ge values were 256.7, 228.6, and $222.6(\mathrm{~g} / \mathrm{kwh})$. Compared to the limit optimal value $215(\mathrm{~g} / \mathrm{kwh})$, the ge value of the PHHE system with GA was pretty good. The result illustrated the parameters matching course was useful and necessary.

Because the optimization course did not take the fuel consumption as the only object, the inconspicuous improvement in the energy saving effect was reasonable.

Besides, the motions of the mechanical equipment were tracked to check the influence brought by the pressure replacement in potential energy recovery under the heavy working condition as in Figure 7.

After the boom falling down process, the final location error was almost none and the time error was about

$$
\text { error }_{\mathrm{bt}}=\frac{11.33-11.02}{11.02-8.85} \times 100 \%=14.29 \% \text {, }
$$

where error $_{\mathrm{bt}}$ was the final time error of the rod displacement between the normal and the hybrid systems. The time error was a little obvious but still acceptable. Additional only the motion was under the same control signal. The operator could 


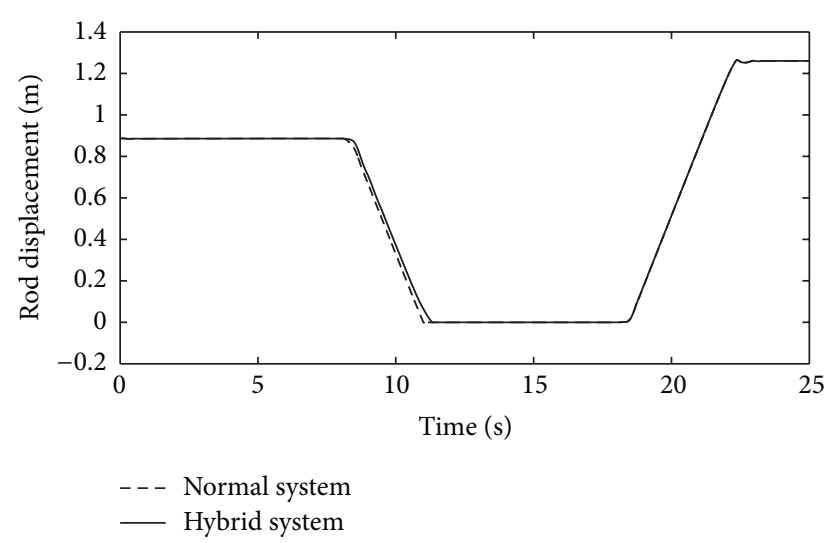

FIgURE 7: The rod displacement of the boom.

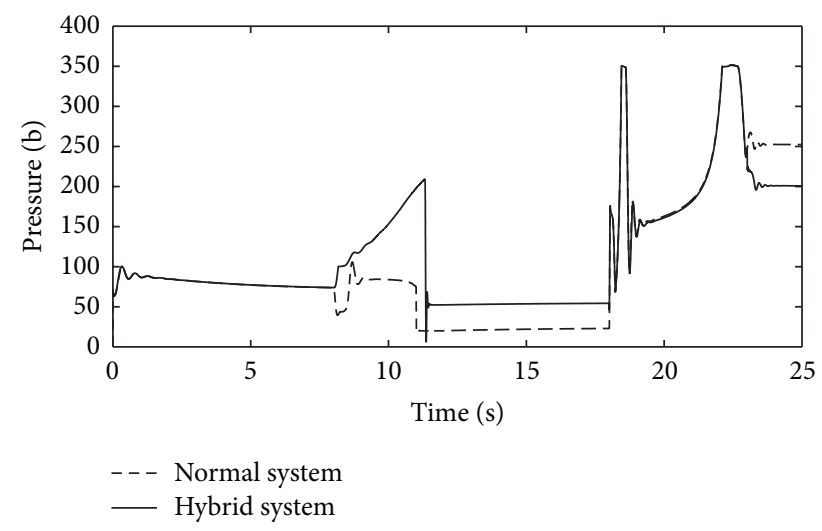

FIgURE 8: The pressure of the chamber without rod.

adjust the operation style to satisfy the action requirements easily in real work condition.

Figure 8, respectively, showed the pressure difference in hydraulic pipeline of the cylinder which proved that the energy recovery system only worked during the boom falling down.

\section{Conclusion}

The parameter matching method proposed in this paper took the storage unit as the key component. During the matching course, the energy saving effect, working ability, and the economy were all considered. The method was especially for the hydraulic hybrid excavator and useful. From the result of the simulation, we could conclude that: (1) the parameter matching method brought an obvious saving effect in fuel consumption (nearly 15\%); (2) the motion of the excavator was less affected; (3) the GA optimization made the parameters more accurate for the parallel hydraulic hybrid system.

\section{Acknowledgment}

This research is sponsored by the National High-Tech R\&D Program of China (Grant no. 2010AA044401).

\section{References}

[1] D. Wang, C. Guan, S. Pan, M. Zhang, and X. Lin, "Performance analysis of hydraulic excavator powertrain hybridization," Automation in Construction, vol. 18, no. 3, pp. 249-257, 2009.

[2] D. Jiuyu, Y. Shihua, and W. Chao, "The application and development of hydraulic hybrid powertrain of vehicle," Machine Tool \& Hydraulics, vol. 37, no. 2, pp. 181-184, 2009.

[3] T. Lin, Q. Wang, B. Hu, and W. Gong, "Research on the energy regeneration systems for hybrid hydraulic excavators," Automation in Construction, vol. 19, no. 8, pp. 1016-1026, 2010.

[4] P. Matheson and J. Stecki, "Development and simulation of a hydraulic-hybrid powertrain for use in commercial heavy vehicles," SAE Technical Paper 2003-01-3370, New York, NY, USA, 2003.

[5] M. Kokkolaras, Z. Mourelatos, and L. Louca, "Design under uncertainty and assessment of performance reliability of a dualuse medium truck with hydraulic-hybrid powertrain and fuel cell auxiliary power unit," SAE Technical Paper 2005-01-1396, New York, NY, USA, 2005.

[6] D. Xin, Z. Chenning, and L. Xincheng, "Energy recovery system simulation and research of hybrid hydraulic excavator," Journal of Beijing Technology and Business University, vol. 28, no. 1, pp. 43-48, 2010.

[7] I. Y. Jong, K. K. Ahn, and Q. T. Dinh, "A study on an energy saving electro-hydraulic excavator," in Proceedings of the ICROS-SICE International Joint Conference, pp. 3825-3830, Fukuoka,Japan, August 2009.

[8] M. Zhang, Q. Wang, and C. Guan, "Simulation research of parallel hydraulic hybrid excavator," China Mechanical Engineering, vol. 21, no. 16, pp. 1932-1935, 2010.

[9] Q. Xiao, Q. Wang, and Y. Zhang, "Control strategies of power system in hybrid hydraulic excavator," Automation in Construction, vol. 17, no. 4, pp. 361-367, 2008.

[10] X. Lin, C. Guan, S. Pan, and D. Wang, "Parameters matching method for parallel hybrid hydraulic excavators," Journal of Agricultural Machinery, vol. 40, no. 6, pp. 28-32, 2009.

[11] H. Yuanjun, Y. Chengliang, and Z. Jianwu, "Parameter matching of parallel hybrid electric city-bus powertrain system," Journal of Shanghai Jiaotong University, vol. 41, no. 2, pp. 272-277, 2007.

[12] S. Hui, "Multi-objective optimization for hydraulic hybrid vehicle based on adaptive simulated annealing genetic algorithm," Engineering Applications of Artificial Intelligence, vol. 23, no. 1, pp. 27-33, 2010.

[13] A. Amirjanov, "The development of a changing range genetic algorithm," Computer Methods in Applied Mechanics and Engineering, vol. 195, no. 19-22, pp. 2495-2508, 2006.

[14] X. Wang, A. C. Yu, and W. Chen, "Optimal matching on driving system of hydraulic hybrid vehicle," in Proceedings of the International Conference on Advanced in Control Engineering and Information Science (CEIS '11), C. Ran and G. Yang, Eds., vol. 15, pp. 5294-5298, Elsevier, 2011.

[15] X. Lin, S.-X. Pan, and D.-Y. Wang, "Dynamic simulation and optimal control strategy for a parallel hybrid hydraulic excavator," Journal of Zhejiang University A, vol. 9, no. 5, pp. 624-632, 2008. 


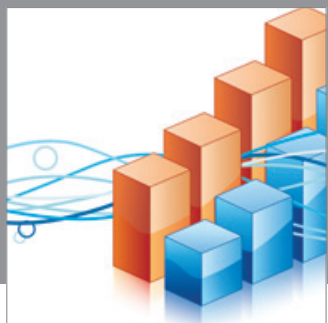

Advances in

Operations Research

mansans

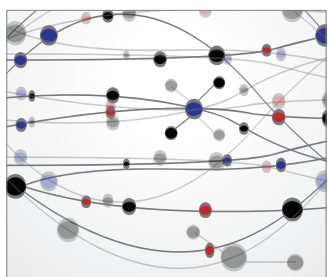

The Scientific World Journal
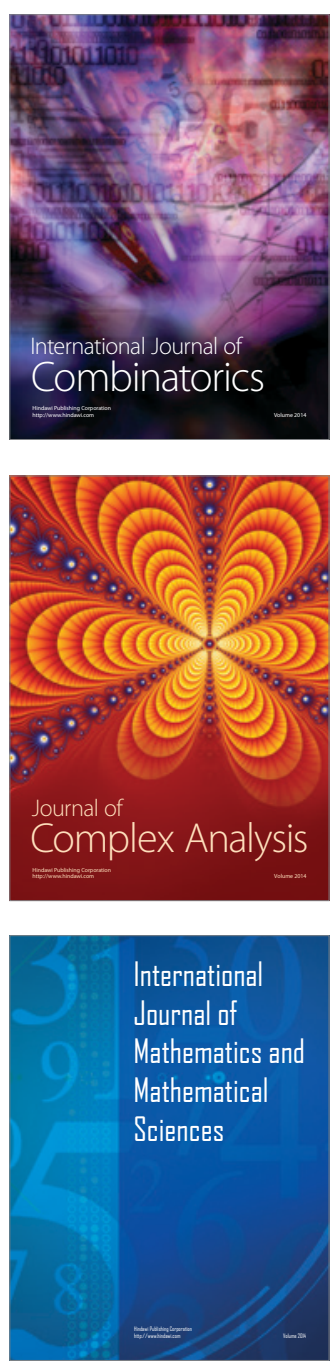
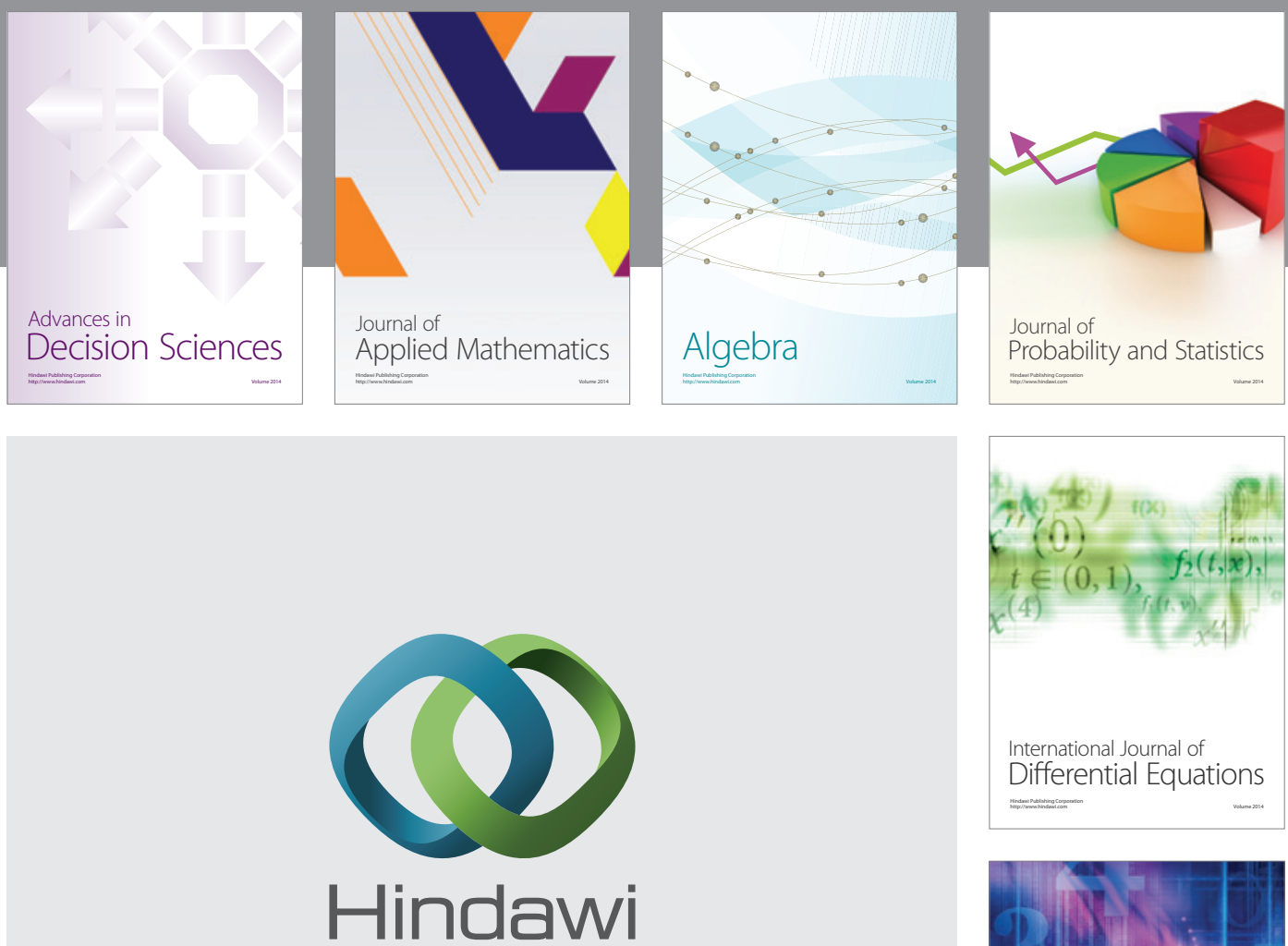

Submit your manuscripts at http://www.hindawi.com
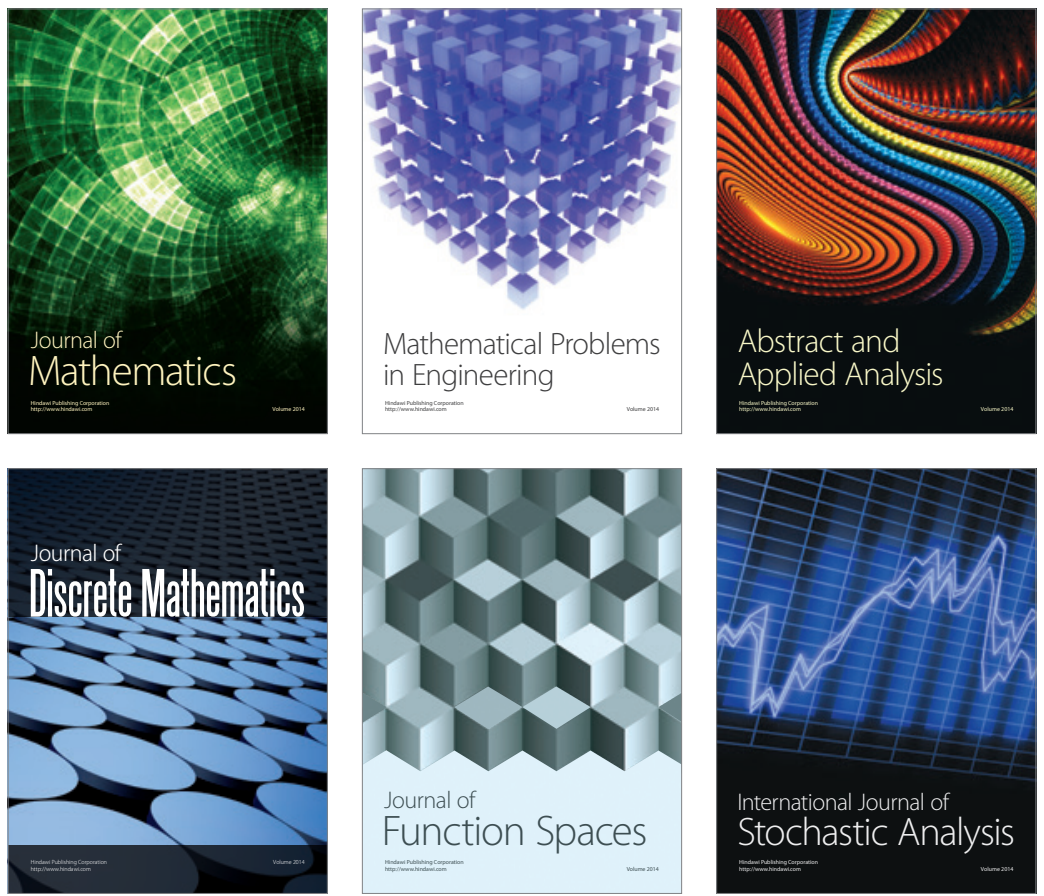

Journal of

Function Spaces

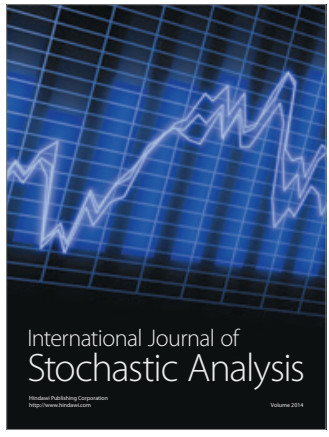

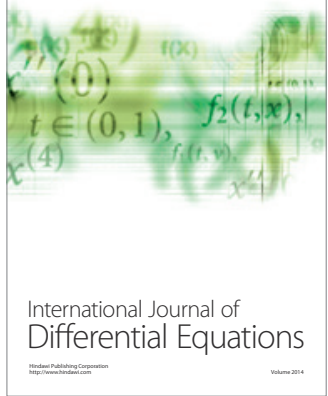
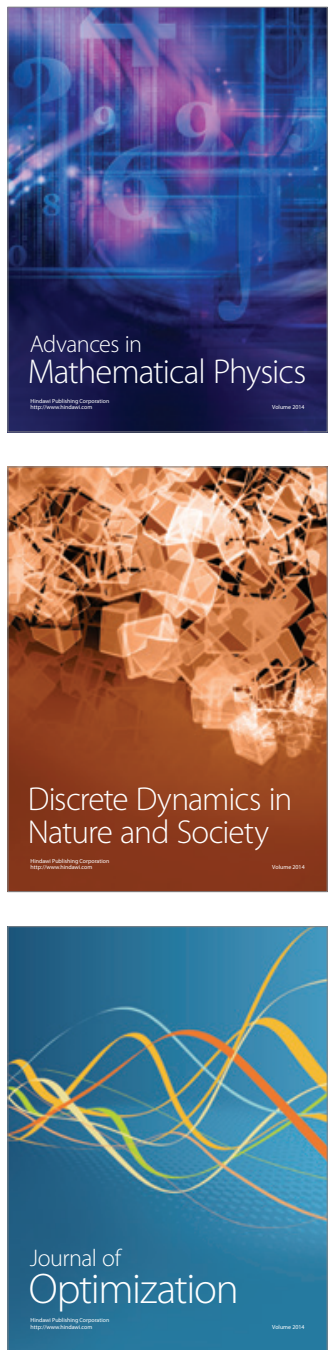